\title{
Anomalous coronary artery anatomy with a single coronary ostium arising from the right coronary: a case report and literature review
}

This article was published in the following Dove Press journal: International Medical Case Reports Journal

\author{
Bothaina Mohammed \\ Abdulshakour' \\ Muhammad Saeed ${ }^{2}$ \\ Mohiuddin M Taher 3,4 \\ 'Department of Radiology, Al-Noor \\ Specialist Hospital, Makkah, Saudi Arabia; \\ ${ }^{2}$ Faculty of Medicine, Department of \\ Radiology, Umm-Al-Qura University, \\ Makkah, Saudi Arabia; ${ }^{3}$ Department of \\ Medical Genetics, Umm-Al-Qura \\ University, Makkah, Saudi Arabia; \\ ${ }^{4}$ Science and Technology Unit, Umm-Al- \\ Qura University, Makkah, Saudi Arabia
}

Correspondence: Mohiuddin M Taher College of Medicine, Al-Abidiya Campus, Umm-Al-Qura University, Taif Road, 21955 Makkah, Saudi Arabia Email TMMohiuddin@uqu.edu.sa

Bothaina Mohammed Abdulshakour Department of Radiology, Al-Noor Specialist Hospital, 3rd Ring Road, 24242 Makkah, Saudi Arabia

Email bshakour@gmail.com
Purpose: This article reports the case of a single coronary artery with origin from a single ostium in the right sinus of Valsalva (RSOV) with an anomalous course of the left coronary artery anterior to the pulmonary trunk.

Results: We present the case of an anomalous single coronary artery detected incidentally during routine coronary computed tomography (CT) angiography performed by a multislice CT method, using a 64-detector-row scanner. The CT examination revealed that the patient had a single large right coronary artery arising from the right sinus of Valsalva, dividing into the right coronary artery, left main coronary artery (LMCA), and left circumflex artery (LCX). The LMCA turned anteriorly in front of the pulmonary outflow tract, reaching the atrioventricular groove. The LCX artery passed posterior to the aorta (retro-aortic) and then between the left atrium and left ventricular outflow tract to reach its normal course on the left side.

Conclusion: We present a rare case of single coronary artery congenital anomaly from the Makkah region of Saudi Arabia. This kind of coronary artery anomaly in the absence of stenosis could remain silent and asymptomatic.

Keywords: anomalous single-coronary artery, multislice CT (MSCT), solitary coronary ostium, cardiac computed tomography (CCT), coronary angiography, coronary-computed tomography (CT)-angiography

\section{Introduction}

Coronary anomalies are a rare heart condition that affect a small percentage of the general population. Coronary anomalies involve the origin or distribution of the artery and rarely are these anomalies clinically significant. Frequently, coronary artery deformities are related to other cardiac malformations and the diagnosis is made after birth. ${ }^{1}$ In rare cases, coronary artery anomalies are an isolated and asymptomatic cardiac malformation. ${ }^{2,3}$ Very rarely, all three coronary arteries originate from a single coronary ostium; a single coronary artery (SCA) arising from the left aortic sinus is extremely more uncommon than one arising from the right sinus. ${ }^{3,44}$ A SCA in the absence of other major congenital anomalies is very rare with an incidence of $0.024-0.06 \%{ }^{5,6}$ In rare cases, it is not possible to perform catheterization of both coronary arteries because of the absence of one of the arteries arising from the ostium of the coronary sinus. The practice of cardiac computed tomography (CT) allows imaging of the coronary anatomy 3-dimensionally and establishes an additional significance to coronary angiography. Visualization of the origin and course of the 
left and right coronary arteries can be achieved by a multislice CT method. ${ }^{7,8}$ In SCA anomaly, there is only one coronary artery ostium from which both coronary arteries arise with essentially normal peripheral distribution. ${ }^{2,4}$ We present a rare case of SCA (Lipton's type RIIIA) congenital anomaly from the Western region of Saudi Arabia.

\section{Case report}

This study was approved by the Institutional Review Board (IRB) for bioethics of Umm al Qura University, Makkah, Saudi Arabia (IRB number HAPO-02-2019-03-310), and was performed in accordance with the principles of the Declaration of Helsinki. Informed consent was obtained from the patient for publishing the images and the case details. A 49-year-old female patient was referred to our hospital in Makkah (Saudi Arabia) for evaluation of atypical chest pain and shortening of breathing. Her vital signs and physical examination were unremarkable. Blood work showed negative cardiac troponin. Echocardiography revealed well-preserved left ventricle systolic function with mild tricuspid valve regurgitation. The electrocardiogram did not show any ischemic changes. The patient was then referred to the radiology department for cardiac CT angiography.

The CT angiogram demonstrated a SCA arising from the single ostium from the right sinus of Valsalva and dividing into the right coronary artery (RCA), left anterior descending (LAD) artery, and left circumflex artery (LCX). Figure $1(\mathrm{~A}-\mathrm{C})$ shows the multislice CT volumerendered reformatted images. The SCA (Figure 1A, B) arises from the single ostium from the RSOV (Figure 1B) and divides into the RCA (Figure 1A, B), LAD artery, and LCX (Figure 1A-C). The LAD artery turns anteriorly in front of the right ventricular outflow tract (Figure 1C), and the LCX shows a retro-aortic course (Figure 1C). The cross-sectional axial view displaying the pre-pulmonic course of the anomalous left coronary artery, pulmonary artery, and aorta (AO) is shown in Figure 2A. Figure 2(B) shows the cross-sectional axial oblique view of the retroaortic course of the LCX, aortic sinuses, and left ventricle. Cross-sectional axial oblique views showing a single coronary ostium arising from the RSOV and trifurcated into the normally coursed dominant RCA, anomalous prepulmonic LAD artery, retro-aortic LCX, and left ventricle are presented in Figure 3(A, B). Cross-sectional longitudinal oblique views in Figure 4(A-C) show a single coronary ostium (Figure 4A) arising from the RSOV and the pre-pulmonic course of the anomalous left coronary artery (Figure 4A-C), left ventricle (Figure 4A, B), aorta (Figure $4 \mathrm{~A}-\mathrm{C}$ ), and right ventricle (Figure $4 \mathrm{~A}, \mathrm{~B}$ ); the left atrium (Figure 4A, B), retro-aortic LCX (Figure 4C), and dominant RCA (Figure 4C) are also clear.

The patient tolerated the CT procedure well with no immediate complications and left the department in a stable condition. The patent was referred back to the cardiology department for further management. The patent was advised by the cardiologist with regard to the benign nature of this incidental findings and she was advised for regular follow-up.

\section{Discussion}

In Saudi Arabia, radiology units in many centers are using regularly the sensitive cardiac-imaging technologies such as coronary CT angiography to screen and detect these coronary abnormalities, and several reports appeared recently from many parts of Saudi Arabia. ${ }^{1,9-11}$ Consanguineous marriages are common in many Middle Eastern countries including Saudi Arabia, and with around $57.7 \%$ prevalence of consanguinity with first-cousin marriages being the most frequent, we expect higher prevalence of congenital heart diseases in Saudi Arabia. ${ }^{12,13}$ However, a recent retrospective analysis of 6 years of coronary $\mathrm{CT}$ angiography scans showed the coronary artery anomalies were similar to literature data. ${ }^{9}$ However, this abnormality is not very common; few reported cases of a SCA with origin from a single ostium in the right sinus of Valsalva with an anomalous left coronary artery were reported by radiologists. We have searched in the PubMed database for these reported cases and summarize some of the reported cases of anomalous left coronary artery in Table 1.

The most common congenital anomaly is separate origin of the LAD artery and LCX from the left coronary sinus. The second most common anomaly is the origin of the circumflex artery from the right coronary sinus. However, there are several reported cases of anomalous single right artery also reported in other investigations. ${ }^{14}$ Also, several cases of RCA arising from the left aortic sinus have also been reported by coronary angiogram and are benign most of the time, and patients are asymptomatic. ${ }^{3,4,15}$ A solitary, unique origin of the coronary vessels may be linked with sudden cardiac arrest, particularly in cases with an inter-arterial course, and usually these patients complain initially about angina. ${ }^{16}$ The risk factors for myocardial ischemia in anomalous 

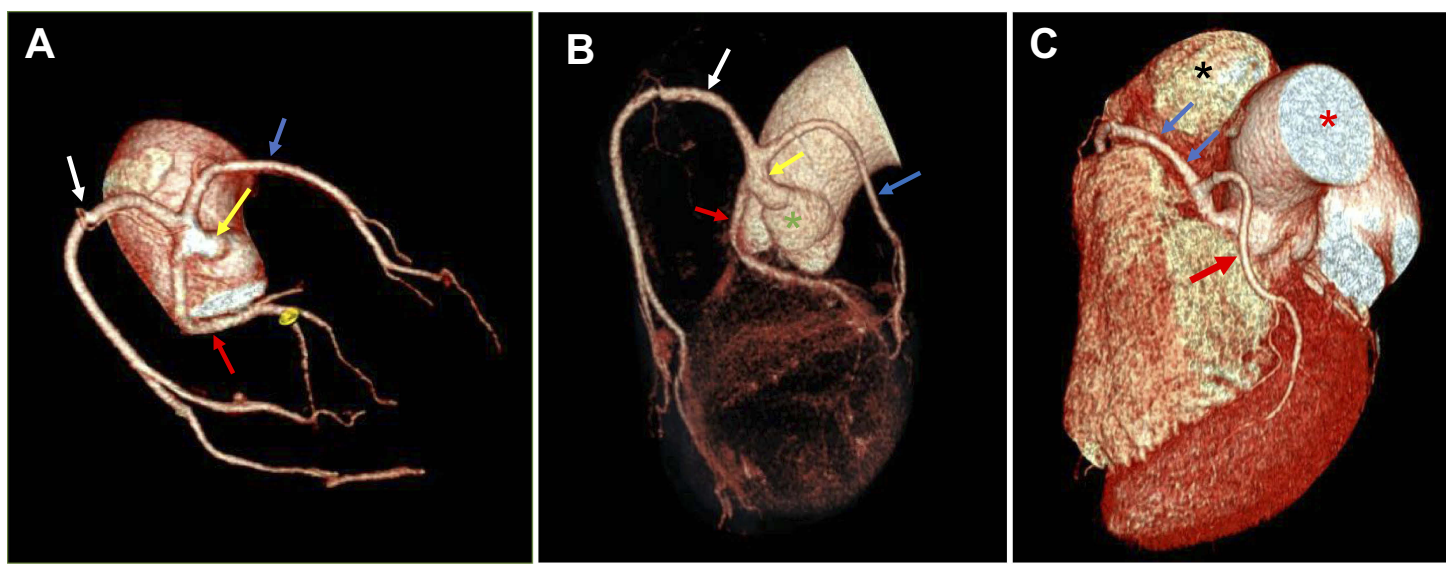

Figure I (A, B, and C) Multislice computed tomography volume-rendered reformatted images showing a single coronary artery (yellow arrow, A and B) arising from the single ostium from the right sinus of Valsalva (green asterisk, B) and dividing into the RCA (white arrow, $\mathbf{A}$ and B), LAD artery (blue arrow) and LCX (red arrow, A-C). The LAD artery turns anteriorly (blue arrows, C) in front of the right ventricular outflow tract (black asterisk, C) and LCX (red arrow, C) showing a retro-aortic course (red asterisk, C). Abbreviations: LAD, left anterior descending; LCX, left circumflex artery; RCA, right coronary artery.
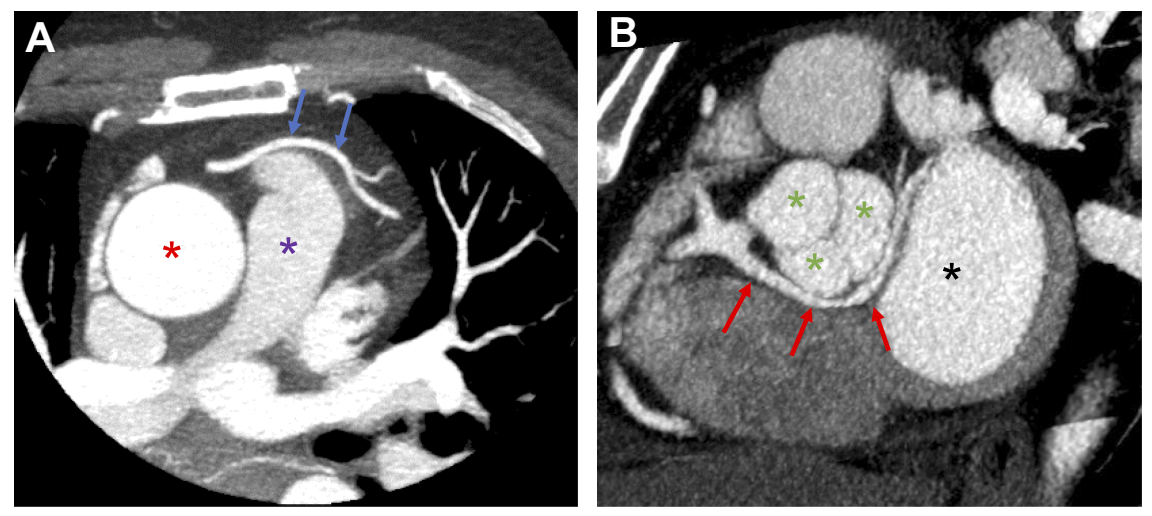

Figure 2 (A) Cross-sectional axial view showing the pre-pulmonic course of the anomalous left coronary artery (blue arrows), pulmonary artery (purple asterisk), and aorta (red asterisk). (B) Cross-sectional axial oblique view showing retro-aortic course of the left circumflex artery (red arrows), aortic sinuses (green asterisks), and left ventricle (black asterisk).

artery patients can be smoking, hypercholesterolemia, a past history of diabetes mellitus, dyslipidemia, obesity, retrosternal chest pain, and a positive family history of premature coronary artery disease. ${ }^{2-4}$ In some cases, the initial troponin test can be negative, and an electrocardiogram will not show any ischemic changes. ${ }^{17}$

The case of a SCA with origin from a single ostium in the right sinus of Valsalva with an anomalous course of the left coronary artery anterior to the pulmonary trunk is presented here. The definition of a heart with a SCA is one in which the entire myocardium is nourished by an artery, regardless of distribution, that arises by one ostium from an arterial trunk. ${ }^{18}$ The current classification system was introduced by Lipton et al, ${ }^{19}$ combining with two previously published systems defined by Smith $^{18}$ and by Ogden and Goodyer. $^{2020}$ In this classification, the origin of the SCA from the right sinus of Valsalva is defined as " $R$ " and from the left sinus of Valsalva as "L". The normal anatomical course of the SCA is defined as "I". The type "II" SCA provides the contralateral coronary artery and crosses the base of the heart to assume its inherent normal position. In the type "III" SCA, after leaving the right coronary sinus of Valsalva, the LAD artery and LCX arise separately from the proximal part of the artery. A further subdivision can be made according to the anatomical course. In type " $\mathrm{A}$ " the main left or right coronary passes anterior to the pulmonary artery, in type " $\mathrm{B}$ " it passes between the aorta and pulmonary artery, and in type " $\mathrm{P}$ " it is posterior to the aorta. The SCA is an extremely exceptionally rare coronary abnormality, and it is usually diagnosed accidentally during conventional coronary artery angiography or on postmortem evaluation. The etiology of SCA is uncertain, however; in 

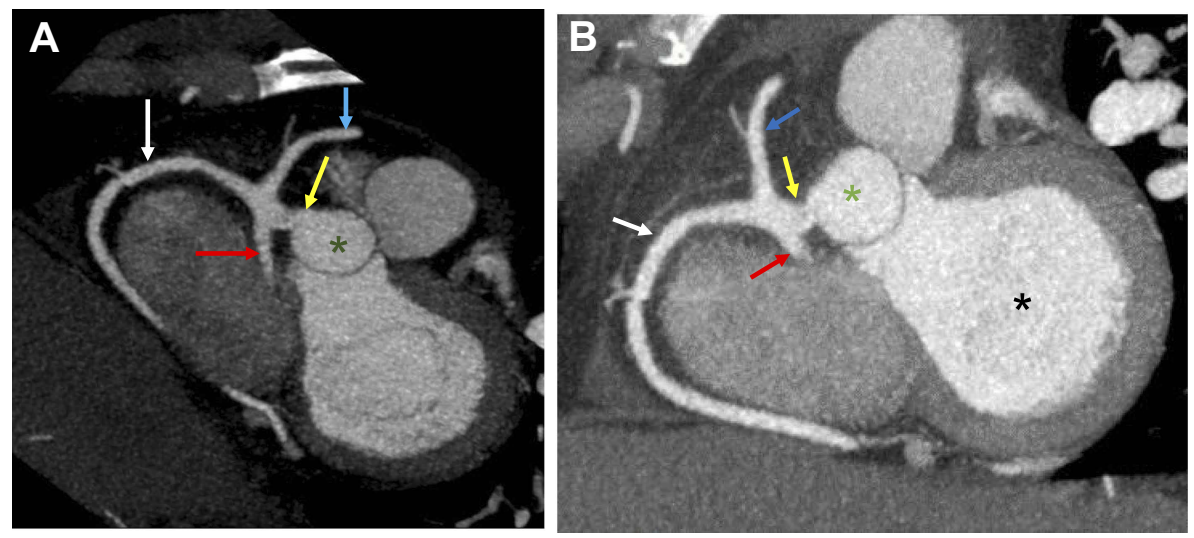

Figure 3 (A and B) Cross-sectional axial oblique view showing a single coronary ostium (yellow arrow) arising from the right sinus of Valsalva (green asterisk) and trifurcated into the normally coursed dominant right coronary artery (white arrow), anomalous pre-pulmonic left anterior descending artery (blue arrow), retro-aortic left circumflex artery (red arrows), and left ventricle (black asterisk).
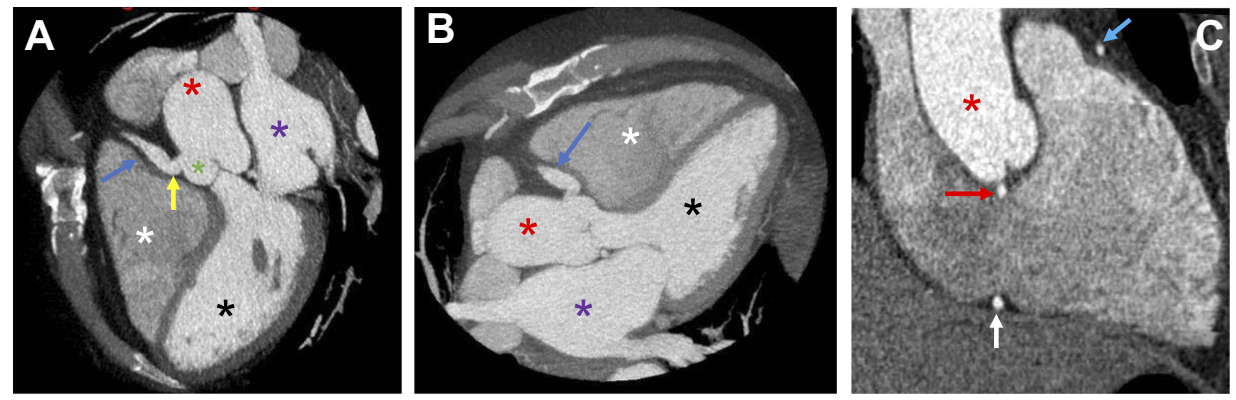

Figure 4 (A, B, and C) Cross-sectional longitudinal oblique views showing a single coronary ostium (yellow arrow, A) arising from the right sinus of Valsalva (green asterisk) and the pre-pulmonic course of the anomalous left coronary artery (blue arrow, A-C), left ventricle (black asterisk, $\mathbf{A}$ and B), aorta (red asterisk, A-C), and right ventricle (white asterisk, A and B), the left atrium (purple asterisk, A and B) and right ventricle (white asterisk, $\mathbf{A}$ and $\mathbf{B}$ ), and the retro-aortic left circumflex artery (red arrow, C) and dominant right coronary artery (white arrow, $\mathbf{C}$ ).

some cases, SCA may lead to life-threatening symptoms, including angina pectoris, myocardial infarction, syncope, cardiac arrhythmias, and congestive heart failure, or this anomaly has been associated with sudden cardiac death in younger patients. ${ }^{19,21}$ Conventional coronary artery angiography is the gold standard for the evaluation of coronary artery disease; however, non-invasive imaging methods, with better spatial resolution, such as multislice CT, can provide anatomical information that may have prognostic value. $^{22,23}$

Left coronary artery arising from RSOV is a serious abnormality, and patients with the intra-arterial type of this anomaly are usually referred to surgery. ${ }^{24}$ Those with the other types are thought to be at low risk and do not require surgery. The patient in this present case complained about chest pain and shortness of breath, maybe because of her mild tricuspid valve regurgitation seen initially by echocardiography or anxiety. There was no compression of the anomalous left coronary artery between the $\mathrm{AO}$ and pulmonary artery, and we believe that this discomfort was less likely caused by the pressure of the aorta on the LAD artery. In the majority of patients with a SCA or anomalous origin of a coronary artery, the native coronary artery provides adequate flow during most situations, because it is a benign lesion. This patient's initial presenting symptoms could be anxiety related or due to mild tricuspid valve regurgitation. For the present case, no grafting is recommended to deliver a stable flow to the left coronary system. In the majority of patients with a SCA or anomalous origin of a coronary artery, the native coronary artery provides adequate flow during most situations, because it is a benign lesion. Surgical correction is generally recommended for patients who have symptoms, or when this anomaly is identified in young age. ${ }^{24}$

\section{Conclusions}

We have diagnosed this patient with a single RCA by dualsource CT angiography with type R, IIIA anomaly. This anomaly is "benign" in the absence of the LAD artery 
Table I Previously published cases with anomalous left coronary artery anatomy arising from the right coronary artery

\begin{tabular}{|c|c|c|c|c|c|}
\hline Clinical Symptoms & Sex & $\begin{array}{l}\text { Age } \\
\text { (years) }\end{array}$ & $\begin{array}{l}\text { Country of } \\
\text { Origin }\end{array}$ & Author & $\begin{array}{l}\text { Reference } \\
\text { No }\end{array}$ \\
\hline Lateral wall $\mathrm{Ml}$ & Male & 74 & Kosovo & Prifti et al & 25 \\
\hline Angina pectoris & Female & 46 & South Africa & Smedema et al & 26 \\
\hline Shortness of breath, fever, and night sweats & Male & 48 & United Kingdom & Neil et al & 21 \\
\hline Unstable angina pectoris & Male & 56 & Canada & Gleeson et al & 17 \\
\hline Sudden onset of retrosternal pain & Male & 69 & The Netherlands & Mihl et al & 27 \\
\hline Angina MI & Female & 63 & Romania & Hailu et al & 28 \\
\hline Multiple atypical chest pain & Female & 59 & USA & Summers et al & 29 \\
\hline Chest pain & Female & 49 & India & Sinha et al & 30 \\
\hline Unstable angina pectoris & Female & 62 & Croatia & Vincelj et al & 31 \\
\hline Exertional dyspnea & Female & 41 & Republic of Korea & Kang et al & 32 \\
\hline Hypertension, angina & Female & 75 & Spain & Tejada et al & 33 \\
\hline Chest discomfort on exertion & Male & 45 & Turkey & Dogan et al & 34 \\
\hline Previous Ml & Female & 47 & Italy & Fiorilli et al & 35 \\
\hline Exercise-induced spells/neurocardiogenic syncope & Female & 16 & USA & Johnson et al & 36 \\
\hline Atypical chest pain & N/A & $\mathrm{N} / \mathrm{A}$ & USA & Anuwatworn et al & 37 \\
\hline Exertional angina & Male & 43 & Omani & Panduranga and Riyami & 38 \\
\hline Chest pain on exertion & Female & 47 & Turkey & Karabay et al & 39 \\
\hline Non-ST-elevated MI & Male & 55 & The Netherlands & Liesting et al & 23 \\
\hline Atypical chest pain & Male & 68 & Turkey & Cakar et al & 40 \\
\hline Inferior wall MI & Male & 68 & India & Subban et al & 41 \\
\hline Chest pain and dyspnea on exertion & Female & 50 & Turkey & Okuyan and Dinckal & 42 \\
\hline Posterolateral MI & Male & 73 & Iran & Kheirkhah et al & 43 \\
\hline MI during exercise & Male & 14 & Japan & Okamoto et al & 44 \\
\hline $\begin{array}{l}\text { Dizziness and syncope on mild exertion, vague left- } \\
\text { sided chest discomfort }\end{array}$ & Female & 46 & Saudi Arabia & Hassan et al & 10 \\
\hline Smoking history, with acute onset typical chest pain & Male & 38 & Saudi Arabia & Al-Bugami et al & 11 \\
\hline Anterior-lateral ST-elevated MI & Male & 71 & Italy & Marchesini et al & 45 \\
\hline Cardiac arrest & Female & 10 & Italy & De Rosa et al & 46 \\
\hline Atrial septal defect & Female & 4 & Saudi Arabia & Al-Muhaya et al & 1 \\
\hline
\end{tabular}

Abbreviations: MI, myocardial infarction; N/A, not available.

between the aorta and pulmonary artery. A SCA is a rare congenital anomaly. Coronary CT angiography with better spatial resolution provides accurate angiographic information on the origin, course, and termination of coronary anomalies non-invasively. A SCA, in the absence of coronary stenosis and an anatomical malignant course, could remain silent and asymptomatic.

\section{Acknowledgments}

The authors wish to thank Mr Hussain Banni, Department of Medical Genetics, and the staff of the Deanship of Scientific Research, Umm-Al-Qura University, Makkah, for their continuous support. This study is partly supported by the National Plan for Science, Technology and Innovation (MAARIFAH), King Abdul Aziz City for Science and Technology (Award Number: 12-MED 2961-10) to Dr MM Taher.

\section{Disclosure}

All authors agreed with the contents of this manuscript and all authors declare no conflicts of interest in this work.

\section{References}

1. Al-Muhaya MA, Syed A, Najjar AHA, Mofeed M, Al-Mutairi M. Anomalous origin of circumflex coronary artery from right pulmonary artery associated with atrial septal defect. J Saudi Heart Assoc. 2017;29:219-222. doi:10.1016/j.jsha.2017.02.001

2. Cieslinski G, Rapprich B, Kober G. Coronary anomalies: incidence and importance. Clin Cardiol. 1993;16:711-715. doi:10.1002/ clc. 4960161005

3. Angelini P. Coronary artery anomalies: an entity in search of an identity. Circulation. 2007;115:1296-1305. doi:10.1161/CIRCULATIONA HA.106.618082

4. Angelini P, Villason S, Chan AV. Coronary artery anomalies: a comprehensive approach. In: Angelini P, editor. Normal and Anomalous Coronary Arteries in Humans. Philadelphia: Lippincott Williams \& Wilkins; 1999:42. 
5. Desmet W, Vanhaecke J, Vrolix M, et al. Isolated single coronary artery: a review of 50,000 consecutive coronary angiographies. Eur Heart J. 1992;13:1637-1640. doi:10.1093/oxfordjournals.eurheartj. a060117

6. Shirani J, Roberts WC. Solitary coronary ostium in the aorta in the absence of other major congenital cardiovascular anomalies. $J \mathrm{Am}$ Coll Cardiol. 1993;21:137-143. doi:10.1016/0735-1097(93)90728-J

7. Schmid M, Achenbach S, Ludwig J, et al. Visualization of coronary artery anomalies by contrast enhanced multi-detector row spiral computed tomography. Int $J$ Cardiol. 2006;111:430-435. doi:10.1016/j.ijcard.2005.08.027

8. Aldana-Sepulveda N, Restrepo CS, Kimura-Hayama E. Single coronary artery: spectrum of imaging findings with multidetector CT. J Cardiovasc Comput Tomogr. 2013;7:391-399. doi:10.1016/j. ject.2013.11.009

9. Smettei OA, Abazid RM, Sayed S. The prevalence of coronary artery anomalies in Qassim province detected by cardiac computed tomography angiography. $J$ Saudi Heart Assoc. 2017;29:84-89. doi:10.1016/j.jsha.2016.07.006

10. Hassan WS, Al-Habeeb WA, El-Shaer FE, Al-Halees ZY. Exertional dizziness and syncope caused by anomalous left coronary artery origin from the right sinus of valsalva. Saudi Med J. 2004;25:1720-1722.

11. Al-Bugami S, Althobaiti MW, Alrahemi J, Alsaiedi AJ, Al-Kashkari W. Coronary intervention of an anomalous left main coronary artery arising from the right sinus of valsalva presented as acute coronary syndrome. J Cardiol Curr Res. 2016;5:00184. doi:10.15406/ jccr.2016.05.00184

12. El-Hazmi MA, al-Swailem AR, Warsy AS, al-Swailem AM, Sulaimani R, al-Meshari AA. Consanguinity among the Saudi Arabian population. J Med Genet. 1995;32:623-626.

13. Hamamy HA, Masri AT, Al-Hadidy AM, Ajlouni KM. Consanguinity and genetic disorders. Profile from Jordan. Saudi Med J. 2007;28:1015-1017.

14. Dahdouh Z, Roule V, Fadel BM, Grollier G. Anomalous right coronary artery originating from the mid left anterior descending artery. Indian Heart J. 2015;67:604-606. doi:10.1016/j.ihj.2015.07.052

15. Assiri AS. Acute coronary syndrome caused by anomalous origin of the right coronary artery from the left sinus of Valsalva. West Afr $J$ Med. 2005;24:278-279.

16. Click RL, Holmes DR Jr., Vlietstra RE, Kosinski AS, Kronmal RA. Anomalous coronary arteries: location, degree of atherosclerosis and effect on survival - a report from the coronary artery surgery study. J Am Coll Cardiol. 1989;13(3):531-537.

17. Gleeson T, Thiessen R, Wood D, Mayo JR. Single coronary artery from the right aortic sinus of Valsalva with anomalous pre-pulmonic course of the left coronary artery. Can J Cardiol. 2009;25:e136-8.

18. Smith JC. Review of single-coronary artery with review of two cases. Circulation. 1950;1:1168-1175.

19. Lipton MJ, Barry WH, Obrez I, Silverman JF, Wexler L. Isolated single-coronary artery: diagnosis, angiographic classification and clinical significance. Radiology. 1979;130:39-47. doi:10.1148/ 130.1.39

20. Ogden JA, Goodyer AV. Patterns of distribution of the single coronary artery. Yale J Biol Med. 1970;43:11-21.

21. Neil D, Bonser R, Townend J. Coronary arteries from a single coronary ostium in the right coronary sinus: a previously unreported anatomy. Heart. 2000;83:e9. doi:10.1136/heart.83.5.e9

22. Ropers D, Moshage W, Daniel WG, Jessl J, Gottwik M, Achenbach S. Visualization of coronary artery anomalies and their anatomic course by contrast-enhanced electron beam tomography and three-dimensional reconstruction. Am J Cardiol. 2001;87:87.

23. Liesting C, Brugts JJ, Kofflard MJ, Dirkali A. Acute coronary syndrome in a patient artery from the right sinus of Valsalva. World J Cardiol. 2012;4:264-266. doi:10.4330/wjc.v4.i8.264
24. Carrel T. Surgical treatment of anomalous aortic origin of coronary arteries: the reimplantation technique and its modifications. Operative Tech Thoracic Cardiovasc Surg. 2016 Autumn;21(3):178-201. doi:10.1053/j.optechstcvs.2017.06.001

25. Prifti E, Ademaj F, Krakulli K, Rruci E, Zeka M, Demiraj A. A rare coronary anomaly consisting of a single right coronary ostium in an adult undergoing surgical coronary revascularization: a case report and review of the literature. $J$ Med Case Rep. 2016;10:190. doi:10.1186/s13256-016-0977-5

26. Smedema JP, Berlion AE, Morkel H. Myocardial infarcts in a patient with a single right sided coronary ostium and interarterial course of the circumflex artery: the role of multi-modality imaging. Int J Cardiol. 2009;132:e42-4. doi:10.1016/j.ijcard.2007.07.114

27. Mihl C, Alzand BSN, Winkens MH. Case report a rare coronary anomaly: one ostium fits all. Cardiol Res Pract. 2010. Article ID 476760, 3 pages, doi:10. 4061/2010/476760

28. Hailu A, Chin D, Musto C, Fiorilli R, Violini R. Rare co-existence of coronary anomalies: anomaly of origin and distribution together with anomaly of intrinsic coronary artery anomaly. Ethiop Med J. 2017;55:73-76.

29. Summers MR, Najm H, Gentry JL, Jaber WA. Exercise N-13 cardiac positron emission tomography myocardial perfusion imaging detecting ischemia in an adult patient with anomalous aortic origin of the left main coronary artery from the right coronary sinus. $J \mathrm{Nucl}$ Cardiol. 2018;25(4):1415-1417. doi:10.1007/s12350-017-0983-Z

30. Sinha SK, Mishra V, Abdali N, Singh K, Jha MJ, Kumar A. A rare case of angina pectoris with the longest ectopic left main coronary artery arising from right sinus of valsalva and a prepulmonic course. Case Rep Cardiol. 2017;2017:5483257.

31. Vincelj J, Todorović N, Marusić P, Puksić S. Anomalous origin of the left coronary artery from the right sinus of Valsalva in a 62-year-old woman with unstable angina pectoris: a case report. Int $J$ Cardiol. 2010;142(3):e35-7. doi:10.1016/j.ijcard.2008.11.182

32. Kang WC, Chung WJ, Choi $\mathrm{CH}$, et al. A rare case of anomalous left coronary artery from the pulmonary artery (ALCAPA) presenting congestive heart failure in an adult. Int J Cardiol. 2007;115:e63-7. doi:10.1016/j.ijcard.2006.07.194

33. Tejada JG, Hernandez F, Sanchez I, Martin-Asenjo R. Stenting of anomalous left main coronary artery arising from the right sinus of Valsalva: a case report. Int $J$ Cardiol. 2007;119:266-267. doi:10.1016/j.ijcard.2006.07.149

34. Dogan SM, Gursurer M, Aydin M, Gocer H, Cabuk M, Dursun A. Myocardial ischemia caused by a coronary anomaly left anterior descending coronary artery arising from right sinus of valsalva. Int J Cardiol. 2006;112:e57-9. doi:10.1016/j.jicard.2006.03.063

35. Fiorilli R, Argento G, Lisanti P, Serino W. Single coronary artery: a case report. G Ital Cardiol. 1998;28:1021-1024.

36. Johnson JN, Bonnichsen CR, Julsrud PR, Burkhart HM, Hagler DJ. Single coronary artery giving rise to an intraseptal left coronary artery in a patient presenting with neurocardiogenic syncope. Cardiol Young. 2011;21:572-576. doi:10.1017/S1047951111000606

37. Anuwatworn A, Karta P, Yee J, Li S, Kumar V, Steffen K. Single coronary artery arising from the right sinus of valsalva and the role of coronary computed tomography angiography. $S$ D Med. 2018;71:130-132.

38. Panduranga P, Riyami A. Single coronary artery from right aortic sinus giving rise to left main coronary artery and a hypoplastic right coronary artery. J Invasive Cardiol. 2010;22:E112-E114.

39. Karabay KO, Bagirtan B, Geceer G, Yildiz A, Bektasoglu G. Anomalous the left main coronary artery originating from the right coronary artery. Int $J$ Angiol. 2016;25:e49-e50. doi:10.1055/s-00341378128

40. Cakar MA, Tatli E, Ozalp B, Gunduz H. Percutaneous coronary intervention of a single coronary artery arising from the right sinus of valsalva. Vasc Health Risk Manag. 2010;6:1077-1078. 
41. Subban V, Victor SM, Ajit MS, Kalidoss L. Single coronary artery from the right coronary sinus with proximal origin of the left anterior descending coronary artery and left circumflex as distal continuation of the right coronary artery: a rare variant. Card J Afr. 2012;23:e134. doi:10.5830/CVJA-2012-034

42. Okuyan E, Dinckal MH. Left main coronary artery arising from right sinus of valsalva: a rare congenital anomaly associated with distal vasospasm. Kardiol Pol. 2011;69:505-507.

43. Kheirkhah J, Sadeghipour P, Kouchaki A. An anomalous origin of left anterior descending coronary artery from right coronary artery in a patient with acute coronary syndrome. J Tehran Heart Cent. $2011 ; 6: 217-219$
44. Okamoto R, Saito K, Miyahara M, et al. Acute myocardial infarction in a patient with anomalous left coronary artery origin and primary antiphospholipid syndrome. Jpn Circ J. 2000;64:214-217. doi: $10.1253 /$ jcj.64.214

45. Marchesini J, Campo G, Righi R, Benea G, Ferrari R. Coronary artery anomalies presenting with ST-segment elevation myocardial infarction. Clin Pract. 2011;1:e107. doi:10.4081/cp.2011. e107

46. De Rosa G, Piastra M, Pardeo M, Caresta E, Capelli A. Exerciseunrelated sudden death as the first event of anomalous origin of the left coronary artery from the right aortic sinus. J Emerg Med. 2005;29:437-441. doi:10.1016/j.jemermed.2005.07.001

\section{Publish your work in this journal}

The International Medical Case Reports Journal is an international, peer-reviewed open-access journal publishing original case reports from all medical specialties. Previously unpublished medical posters are also accepted relating to any area of clinical or preclinical science. Submissions should not normally exceed 2,000 words or 4 published pages including figures, diagrams and references. The manuscript management system is completely online and includes a very quick and fair peer-review system, which is all easy to use. Visit http://www.dovepress.com/testimonials.php to read real quotes from published authors. 